\title{
Institutionalizing an astronomical internationalism in the long run
}

\author{
Arnaud Saint-Martin \\ Centre Européen de Sociologie et de Science Politique, \\ Centre National de la Recherche Scientifique, École des Hautes Études en Sciences Sociales, \\ Université Paris 1-Panthéon Sorbonne, 54, boulevard Raspail, 75006 Paris, France \\ email: arnaud.saint-martin@cnrs.fr
}

\begin{abstract}
A century of existence: it may seem short on the time-scale of the evolution of the universe, but very consequential to that of a scientific association. The fact that the IAU may be able to celebrate such a milestone is in itself a meritorious collective achievement, for it was not obvious at the very beginning that this organization was going to last more than a decade. Drawing on the historical sociology of scientific institutions, my paper will discuss the moral economy through which the IAU - and its dated but persistent form of scientific internationalism - has stabilized and maintained its identity since its creation in 1919, under the unifying auspices of a global scientific object to be known as: Under One Sky.
\end{abstract}

Keywords. scientific internationalism, ethos, disinterestedness, scientific community

\section{Introduction}

I have been invited to reflect as a sociologist of science and technology on the centenary of a scientific organization of which I am not a member, of which I only know the very first years of its establishment in the 1920s, and this is all about a science that I do not practise, or do so only as a mere amateur with my 200-mm telescope: this is a very uncomfortable situation. Among all possible subjects, I have chosen, nevertheless, to deal with the question of "scientific internationalism", which is one of the raisons d'être of the International Astronomical Union (Blaauw 1994). I will argue that scientific internationalism is not a stable category nor a self-evident set of ideas and ideals; its meanings are multiple and may have changed in relation to historical contexts. But at the same time, that doesn't prevent the possibility of a consensus on its profound significance.

Scientific internationalism is something that is esteemed by the members of the world astronomical community, something that needs to be defended and promoted, which must be performed in practical situations by those who believe in this principle, who care about it, whether through their participation in the IAU or in cooperative programmes of an international character. These cultural values and repertoires of beliefs may have an effect in reality, they participate in the definition of the situation, in the establishment of a science that is experienced as truly "international" by aspiration as much as by functional necessity. And finally, internationalism has a place in the imagination of astronomy as a "community" within borders (see Anderson 1991). I will explore here some aspects of this historical attachment to scientific internationalism. First, I will provide an overview of the uses and performances of scientific internationalism, and then I will discuss the challenges of the promotion of astronomy as an international enterprise committed to a certain definition of the ethos of modern science. 


\section{The uses and performances of "scientific internationalism"}

For the purposes of the presentation, I will be schematic. I have identified several uses of the internationalist idiom. I mentioned a first use which corresponds to the long history of cooperation among astronomers. One may find some precedents at the turn of the 20th century, such as the Astrographic Chart and the Union for Co-Operation in Solar Research. The cooperation through focused research programmes was not necessarily justified by the rise of the internationalist doxa, but it will be more so after the 1920s. There are plenty of examples in the history of the sciences in the inter-war period of references to "internationalism" that were also coloured by national or nationalist claims (internationalism was acceptable for the Allied nations, but without the scientists of the "Central Powers") (Forman 1973). Yesterday as well as today, endorsing "universalism" through "scientific internationalism" can be a tactic to enhance the prestige of the nation one is supposed to represent. Every member deals with this ambiguity in his/her own way, but in all circumstances displaying chauvinism is pretty impolite. At the same time, these feelings may be exhibited by the patriots of science without being overly nationalistic.

Scientific internationalism is also the ingredient of a professional ideology to be shared by astronomers all around the world. No-one wakes up in the morning proclaiming to be an internationalist in science; this is not a natural inclination. This is more like a natural and taken-for-granted disposition which is embedded into a scientific habitus; in other words, the result of a professional socialization and training, in astronomy departments, laboratories, observatories or even the International School for Young Astronomers, all of which recognize internationalism as a central value. That is a key part of a professional ethos, a core-set of "institutional imperatives" operating together, among which - and here I refer to the definition suggested by sociologist of science Robert K. Merton (Merton 1942) - are "communism", "universalism", "disinterestedness" and "organized skepticism". On the basis of many lines of evidence, I would say that this "normative structure" has enabled the "uniting" of a particular scientific community for 100 years. Scientists' attachment to this partly explains the resilience of a certain sense of membership within the community to which they belong. These values are not idealistic; they are experienced in daily scientific life. They are also included in the folklore and institutional memory of international astronomy, with its "great names" who have been involved in executive committees, its dates, acronyms, photographs of meetings and past symposia.

Scientific internationalism is a key marker of science diplomacy (Saint-Martin 2009) and the promoting of international relations by means of organizations specially dedicated to this purpose. From the beginning, the IAU was the opportunity to invent an "assembly", a "union". As a scientific body governed by an elected executive committee (Oosterhoff 1955, p. 12), the IAU defined scientific goals and means during the first meeting in Rome in 1922 and those that took place thereafter: the emphasis was placed on resolutions and standardization, the maintenance of centralized structures (International Latitude Service, the International Time Bureau), the distribution of tasks according to each other's capacities, the establishment of commissions. The management of "international relations" was critical in the performance of astronomers' cultural authority as "officials" and representative of their government, who allow them to participate in congresses. This diplomacy also concerns the way astronomers interact with each other. In the 1920s, the IAU consolidated and formalized social networks that had already been established through past scientific meetings and exchanges. This is an extension of the "congressist movement" which grew during the Belle Époque and afterwards (Rasmussen 1995; Schofer 2003), and shaped the sociability of an elite of dominant, male, bourgeois, Western-centered cosmopolitan scientists in a suit and tie. Official social events and scientific courtesy trips were part of their representational activity. 
Last but not least, as is the case with national prestige, scientific internationalism can be manipulated as a rhetoric tool for gaining public support. That is a mantra for astronomy advocacy and lobbying groups. One may do things by invoking such noble and performative words; for instance, explaining to the governments and the politicians the astronomical expenses of the James Webb Space Telescope, the space probes sent into the solar system with the substantial help of the space agencies, large-scale infrastructures and ESO's large ground-based facilities like the VLT or the future Extremely Large Telescope. Astronomy is important, but when budgets are under pressure, astronomers must trick their sponsors so that they will be willing to pay the bills. Scientific internationalism, the wonders and beauty of the universe and the celestial bodies, the prestige of astronomy as a science from the dawn of time, those were and still are good reasons to preserve the autonomous space of discovery of astronomy.

But finally, one may wonder whether scientific internationalism might not be some sort of cultural relic within the modern scientific world, which is nowadays structured by large-scale processes, such as globalization, the networked and digitized society, the intensification of the "knowledge economy", etc. When science is pushed to "open up to society" at all levels, when emphasis is placed on innovation and advanced technology, patents and industry research, profitability and commercialization, entrepreneurial and corporate research in the "neo-liberal regime of science and technology" (Forman 2007; Mirowski 2011) - evolution in the field of what is known in Silicon Valley and elsewhere as the "New Space", with space mining or lunar colonization 2.0 as promises of huge markets in the coming decades. In brief, when these developments are defined as priorities in science policy agendas all around the world, the idea of an autonomous, independent, universal science, without national frontiers or direct or short-term benefits, is quite hard to sell.

\section{Defending the ethos of science and/by means of scientific internationalism}

Fortunately, astronomers know very well how to secure their professional territory and promote their interpretation of internationalism to execute their plans. And there are critical moments when they have no choice but to fight for it. In the mid-fifties - that is, during the Cold War, Marcel Minnaert (1893-1970) stressed the importance of an "international feeling" (Minnaert 1955, p. 9), which helped in maintaining a cohesive group ethos among astronomers of all countries: [I quote] "It is the faith of our life that ultimately there will never be contradictions between the findings of all these scientists, varied in their personalities and nationalities, since Nature is unique and since Truth is unique. And, finally, there emerges, in a purified form, what we may call International Science, which is no more the work of individuals but the work of the community, of humanity as a whole, the noblest expression of the human mind." (Minnaert 1955, p. 11)

This is a suggestive summary of the internationalist doxa. These principles are never more vigorously defended than when they are challenged, or in danger when scientists become aware of their value. These threats may be the result of ideological and political interference, or economic alienation within the capitalist system. Let's take the first case: ideological threats to the normative foundations of the ethos of international astronomy have been numerous. The former IAU president, Sir Arthur Eddington, at the 1938 meeting, was optimistic enough to state that "If in international politics the sky seems heavy with clouds, such a meeting as this at Stockholm is as when the Sun comes forth from behind the clouds. Here we have formed and renewed bonds of friendship which will resist the forces of disruption" (quoted by Oosterhoff 1955, p. 12). 
That very same year, Robert K. Merton introduced the notion of an ethos of modern science. Astronomical internationalism is to a certain extent an avatar of the universalism in the ethos of science, which implies "free access to scientific pursuits is a functional imperative", but, according to Merton, "Particularly in times of international conflict, when the dominant definition of the situation is such as to emphasize national loyalties, the man [and woman!] of science is subjected to conflicting imperatives of scientific universalism and ethnocentric particularism." That's why, when the climate of opinion or the geopolitical situation is alarming, scientists are so quick to publicly stand for the moral economy of independent and without-borders science, to which they knowingly adhere. Some very recent examples can be found: remember, for instance, the IAU's strong reaction (made public in January 2017) to the US executive order banning access from seven countries* - which posed a threat to international collaboration and mobility of astronomers - or the participation of many astronomers and their organizations within the March for Science in April 2017.

I mentioned other threats to the practice of astronomy, some of which are economic in nature. Preserving the sky as an unsaleable common entity, whose modes of existence must be documented and explained; defending astronomical knowledge for itself, as an end in itself; and finally organizing a community dedicated to this enterprise, away from voracious economic interests. These inclinations are rooted in the functional imperative of communism, which implies that "the Universe is not for sale" (Andersen 2004, p. 11), and this is the reason why so many astronomers, both professionals and amateurs, are still eager to highlight the disinterestedness, intrinsic aesthetics and moral value of the contemplation of the universe. The Resolution, published during the International Year of Astronomy 2009, entitled "In Defence of the Night and the Right to Starlight", exemplifies this: [I quote] "An unpolluted night sky that allows the enjoyment and contemplation of the firmament should be considered a fundamental socio-cultural and environmental right, and that the progressive degradation of the night sky should be regarded as a fundamental loss" (Green et al. 2015, p. 185). Protecting existing and potential observatory sites: this is the Sisyphean mission of the Inter-Division Commission B7, and one might say that it does not lack bravery.

\section{Conclusion}

Scientific internationalism is a never-ending collective utopia, whose history is based solely on the belief in its value. The challenges are great, but the IAU's tremendous expansion - with its 13000 members - suggests that this enterprise is doing well. Astronomy is one of the few sciences whose scientific and cultural authority is not really contested, if one put the creationist or Flat Earth delusions aside, however. Astronomy can be configured as a "public science", a fundamental science with which the public can easily engage, through basic observations during summertime or "nuits des étoiles", exhibitions like "From Earth to the Universe" organized during the IYA 2009 (Arcand \& Watzke 2011), or events such as this conference. The main difficulty is to find the material and institutional resources to make this disinterestedness and this particular sense of celestial universalism a reality. The contagious enthusiasm that I have been able to detect in the presentations and discussions in the last congress in Vienna makes me think that the IAU is on the right track for the next century.

\section{Acknowledgements}

I would like to thank David Valls-Gabaud for gently pushing me to work again on a subject on which I hadn't been working for a while.

* www.iau.org/news/announcements/detail/ann17006 


\section{References}

Andersen, J. 2004, in Developing Basic Space Science World-Wide: A Decade of UN/ESA Workshops, W. Wamsteker, R. Albrecht, H. J. Haubold (eds) (New York, Kluwer), p. 11

Anderson, B. 1991 [1983], Imagined Communities: Reflections on the Origin and Spread of Nationalism (London, Verso)

Arcand, K., Watzke, M. 2011, Science Communication, 33, 398

Blaauw, A. 1994, History of the IAU: The Birth and First Half-Century of the International Astronomical Union (Dordrecht: Kluwer)

Forman, P. 1973, Isis, 64, 150

Forman, P. 2007, History and Technology, 23, 1

Green R., Walker C., van Driel W., Alvarez del Castillo E., Garcia B., Metaxa M., Ohishi M., Patat F., Sefako R., Tzioumis A., 2015, in Transactions IAU, Volume XXIXA, Proc. XXIXA IAU General Assembly, August 2015 T. Montmerle (ed) (Cambridge, Cambridge University Press), p. 185

Merton R. K. 1942, Journal of Legal and Political Sociology, 1, 115

Minnaert, 1955, Vistas in Astronomy, 1, p. 9

Mirowski, P. 2011, Science-Mart: Privatizing American Science (Cambridge, Harvard University Press)

Oosterhoff, 1955, Vistas in Astronomy, 1, p. 12

Rasmussen, A. 1995, L'internationale scientifique 1890-1914, Doctoral dissertation (Paris, EHESS)

Saint-Martin, A. 2009, in The Role of Astronomy in Society and Culture D. Valls-Gabaud, A. Boksenberg (eds) (Cambridge, Cambridge University Press), 202

Schofer, E. 2003, American Sociological Review, 68, 730 